\title{
Development of marine landscape maps for the Baltic Sea and the Kattegat using geophysical and hydrographical parameters
}

\author{
Zyad K. Al-Hamdani, Johnny Reker, Jørgen O. Leth, Anu Reijonen, Aarno T. Kotilainen \\ and Grete E. Dinesen
}

The Baltic Sea is one of the largest brackish water bodies in the world (Segerstråle 1957) with a number of basins varying from almost fresh water in the northern part of the Bothnian Bay via the more brackish conditions in the southern part to the saline waters of the Kattegat. The Baltic Sea is subject to severe environmental degradation caused by commercial and leisure activities, including fisheries, dredging, tourism, coastal development and land-based pollution sources. This causes severe pressures on vulnerable marine habitats and natural resources, and a tool for aiding marine management is therefore strongly needed.

The marine landscape concept presented by Roff \&Taylor (2000) is based on the use of available broad-scale geological, physical and hydrographical data to prepare ecologically meaningful maps for areas with little or no biological information. The concept, which was elaborated by Day \& Roff (2000) was applied in UK waters (Connor et al. 2006) before it was adopted by the BALANCE project described here. The aim of developing marine landscape maps is to characterise the marine environment of the Baltic Sea region (the Baltic Sea together with the Kattegat) using geophysical and hydrographical parameters. Such maps can be applied, for example, to an assessment of the Baltic-wide network of marine protected areas, and thus provide a sustainable ecosystem-based approach to the protection of the marine environment from human activities, and contribute to the conservation of marine biodiversity.

The BALANCE project is based on transnational and cross-sectoral co-operation with participants from nine countries surrounding the Baltic Sea as well as Norway (Fig. 1), and is partially financed by the European Union through the BSR INTERREG IIIB programme.

\section{Data collation and harmonisation}

One of the most challenging aspects of marine landscape map production is collating and harmonising data sets from different sources and with different formats. The data sets include: bathymetry, seabed sediment types, the photic zone, ice cover, halocline depth, temperature, current velocity and bottom salinity. The data sets provided by the individual part-

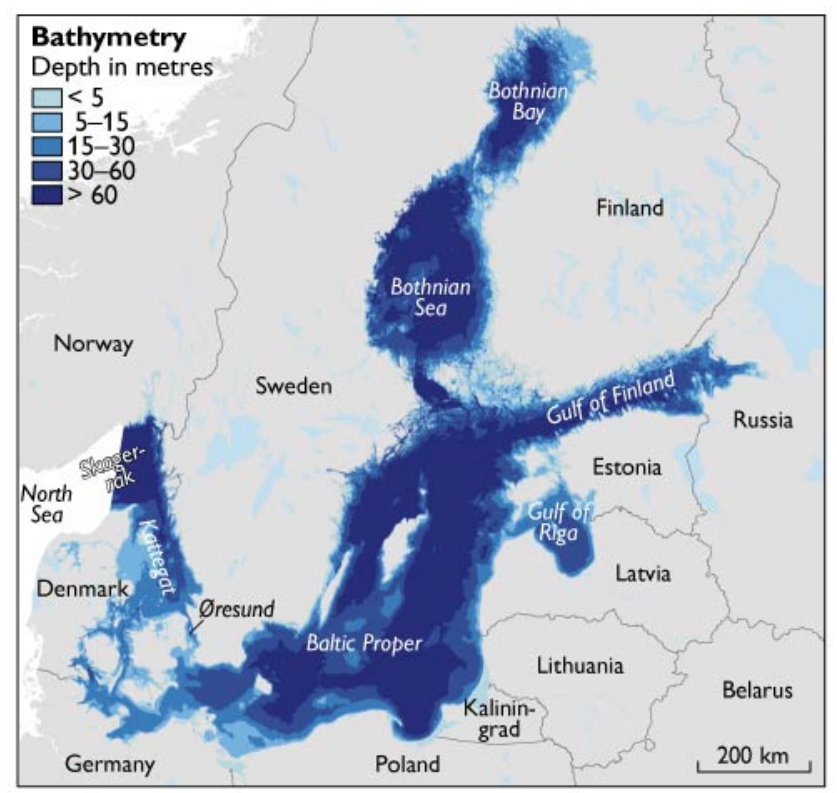

Fig. 1. Bathymetry of the Baltic Sea, the Kattegat and the Skagerrak, the working area of the BALANCE project. Data source: Geological Survey of Denmark and Greenland, Geological Survey of Sweden and Geological Survey of Finland

ners in the BALANCE project were analysed in detail before merging in a GIS platform to produce the final benthic marine landscape map (Al-Hamdani \& Reker in press).

The data sets were obtained through a combination of field measurements and modelling. Other data were considered, but not acquired for the entire area; these include oxygen depletion, stratification, wave exposure and pycnocline depth.

\section{Development of marine landscape maps}

The uniqueness of the Baltic Sea region originates in part from its salinity distribution. A stable salinity gradient and stratification is observed in both vertical and horizontal dimensions. This results in wide biogeographic variation as the water salinity changes from marine in Skagerrak to nearly fresh waters in the Bothnian Bay. Thus a wide variety of complex marine landscapes reflecting the complexity of the in situ regimes of physical factors is expected. The physical factors chosen for defining the marine landscapes in the Baltic Sea 


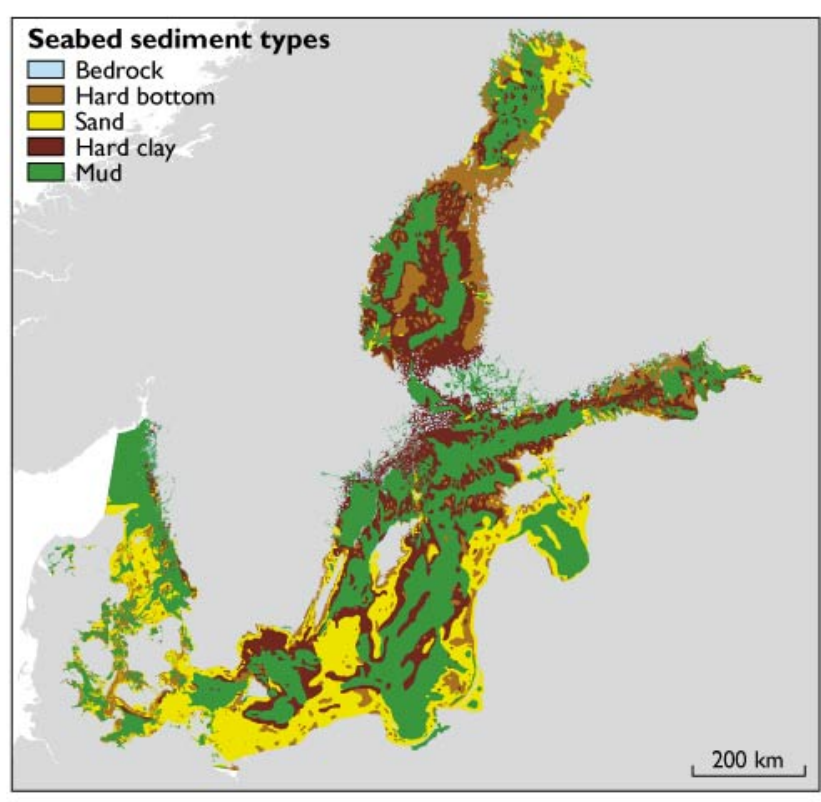

Fig. 2. Map of the seabed sediments. Data source: Geological Survey of Denmark and Greenland, Geological Survey of Sweden and Geological Survey of Finland.

region are considered important for structuring the distribution of major biological assemblages in the region. Three physical parameters were adopted in this work to produce the benthic marine landscape map: sediment type, the photic zone, and bottom salinity. The best way to produce a benthic marine landscape map from a number of different sources is by using raster map algebra in a GIS platform. This method allows the combining of several different parameters stored in separate layers into a single map layer.

One of the major tasks in the production of marine landscape maps for the Baltic Sea region was to split the chosen environmental data sets in such a way as to produce ecologically relevant classes. The justification for the classification of each data layer is explained separately below, bearing in mind that this is the first attempt to classify such features in the Baltic Sea; future amendments are thus to be expected.

\section{Seabed sediment types}

The data sets for this layer were gathered from different governmental and research institutes of the Baltic Sea countries and Norway. The existing data are abundant and very diverse and have been acquired using different field techniques during the past several decades. Seabed sediment maps from offshore and coastal areas exist at a wide range of scales from local (1:20 000) to regional (up to 1:1 000000$)$. Terminology and classifications vary as well, since the nine circum-Baltic nations together with Norway have interpreted their own data according to different national classification schemes.

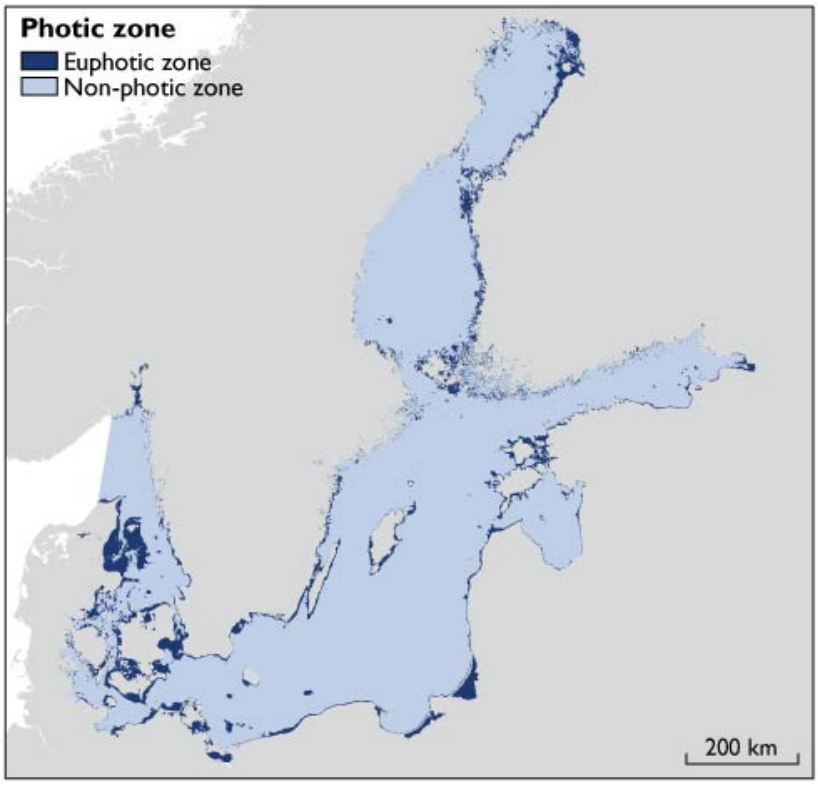

Fig. 3. Map of the photic zones. The original modelled data set is a $620 \mathrm{~m}$ grid of the average Secchi depth measured from March to the end of November for the period from 1980 to 1998. Data source: Danish Hydraulic Institute.

National seabed sediment classification categories needed to be harmonised in order to produce the regional map for seabed sediment types (Fig. 2). The resulting classification scheme consists of five sediment classes, which can be extracted from existing data. These sediment classes are:

1. Hard bottom, including bedrock (crystalline and sedimentary) and bedrock covered with boulders.

2. Hard bottom composite, including complex, patchy hard surface and coarse sand (sometimes also clay to boulders).

3. Sand, including fine to coarse sand (with gravel exposures).

4. Hard clay, sometimes/often/possibly exposed or covered with a thin layer of sand/gravel.

5. Mud, including gyttja-clay to gyttja-silt.

\section{The photic zone}

From an ecological point of view, available light is one of the primary physical factors influencing and structuring the biological communities in the marine environment, as it is the driving force behind primary production by providing energy for photosynthesis. The depth of the euphotic zone is traditionally defined as the depth where $1 \%$ of the surface irradiance (as measured just below the water surface) is available for photosynthesis. This value was calculated by multiplying the actual measured Secchi depths by a factor of 1.9 (A. Erichsen, personal communication 2006). Based on the irradiation depth, the photic zone was split into two intervals: the euphotic zone and the non-photic zone. These two zones 
reflect the significant ecological difference between the shallow-water environment where primary production takes place, and the deeper waters where species and biomass are dominated by fauna and bacteria (Fig. 3).

\section{Bottom salinity}

Salinity is one of the primary physical factors structuring the distribution of species within the Kattegat and the Baltic Sea, varying from almost fresh water in the Bothnian Bay to normal marine waters in Skagerrak (Fig. 4). The classification of the salinity data set and justification of the classification are presented in Table 1.

The three layers, sediment, photic zone, and bottom salinity were combined using the Spatial Analysis tool in the GIS program resulting in the benthic marine landscape map of the Baltic Sea region shown in Fig. 5. This map shows the distribution of 60 marine landscape types each representing different physical conditions at the seabed. The marine landscape map was further analysed with a statistical tool in GIS program to extract the diversity in marine landscape distribution (Fig. 6).

\section{Application of marine landscape maps}

The marine landscape maps developed for the Baltic Sea region are a first approach to a broad-scale, physical characterisation of the marine environment of the Baltic Sea and the Kattegat. It will be used throughout the BALANCE project to assess the representativity of the network of marine protected areas (MPAs) within the Baltic Sea region. This assessment will identify whether some marine landscape

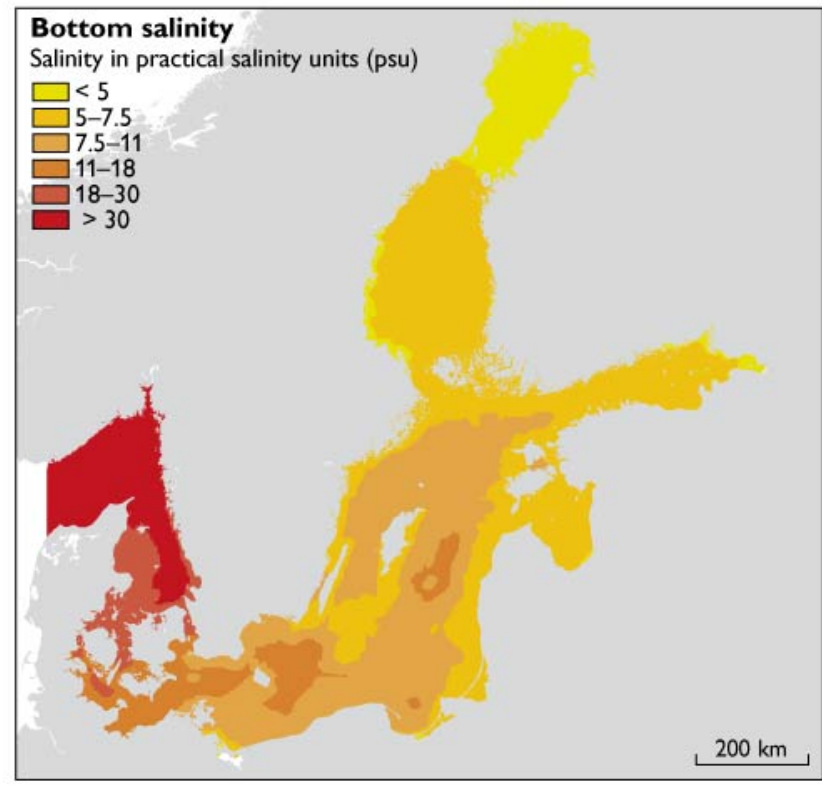

Fig. 4. Map of the bottom salinity. The original modelled data set is a 7.5 $\mathrm{km}$ grid horizontal resolution and 20 vertical layers. The model is based on monthly, averaged values from August 2003 over a period of one year. Data source: National Environmental Research Institute, Denmark.

types are missing or over-represented within the existing MPA network and thus help inform environmental managers whether the existing network is protecting and representing the marine diversity of the Baltic region. The landscape map can also be used to show the complexity of the marine environment within a certain area (Fig. 5) to enhance future management and protection of the marine ecosystem.

In addition to a continuous validation process and confidence rating of the data layers and maps there are many

Table 1. Baltic Sea salinity classification and justification

\begin{tabular}{|c|c|c|}
\hline Interval & Salinity range* & Justification \\
\hline Oligohaline I & $<5$ psu & $\begin{array}{l}\text { This picks up the biogeographic boundary in the Bothnian Bay area. Many freshwater species are able to } \\
\text { survive in salinities below } 5 \text { psu including invertebrates, fish and plants. }\end{array}$ \\
\hline Oligohaline II & $5-7.5$ psu & $\begin{array}{l}7.5 \text { psu equals roughly to the area where Fucus serratus has its distributional boundary (Baltic Proper) } \\
\text { making Fucus vesiculosus the dominating sublittoral brown algae. It is the interval with the lowest number } \\
\text { of species and thus the most vulnerable part of the Baltic Sea. }\end{array}$ \\
\hline Mesohaline I & 7.5-11 psu & $\begin{array}{l}11 \text { psu is the minimum requirement enabling cod (Gadus morhua) eggs to float. As cod is an important } \\
\text { commercial species for the Baltic Sea region this interval is chosen in order to increase applicability of the } \\
\text { marine landscapes map for environmental management. It also helps to separate offshore environment } \\
\text { from coastal areas in large parts of the Baltic Proper. }\end{array}$ \\
\hline Mesohaline II & $11-18$ psu & $\begin{array}{l}18 \mathrm{psu} \text { is the minimum requirement (roughly) for sexual reproduction or limiting distribution of many } \\
\text { marine macroalgae, e.g. Laminaria digitata and Ascophyllum nodosum, and of e.g. echinoderms. The interval } \\
\text { picks up the biogeographic boundary in Øresund. } 18 \mathrm{psu} \text { is also the figure mentioned in the EU Water } \\
\text { Framework Directive further increasing the applicability of the marine landscape maps. }\end{array}$ \\
\hline Polyhaline & $18-30$ psu & $\begin{array}{l}\text { Most marine species are able to survive within this interval. It is also an interval mentioned in the EU } \\
\text { Water Framework Directive. }\end{array}$ \\
\hline Euhaline & $>30$ psu & $\begin{array}{l}\text { Requirement of truly stenohaline species separating the marine parts of the Skagerrak and the North Sea } \\
\text { from the freshwater influenced water masses of the Kattegat and the Baltic Sea region. The interval is also } \\
\text { mentioned in the EU Water Framework Directive. }\end{array}$ \\
\hline
\end{tabular}

* psu: practical salinity units. 


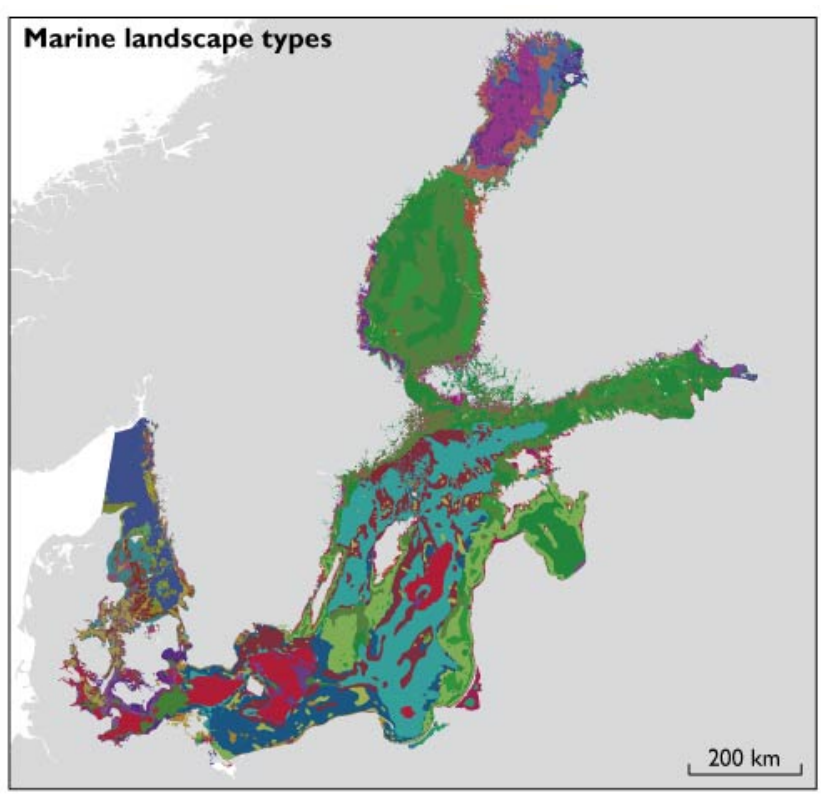

Fig. 5. Map showing the 60 marine landscape types recognised in the Baltic Sea, the Kattegat and the Skagerrak. For further details see AlHamdani \& Reker (in press).

future challenges for the marine landscape maps. These will include adapting them as a tool for various EU directives implementation, using the maps as (1) a strategic tool for planning future field surveys for mapping (e.g. Natura 2000 habitats in the EU Habitats Directive, (2) a physical characterisation of the marine environment in the proposed Marine Strategy Directive, or (3) part of the typologies in the EU Water Framework Directive. The approach described here should, of course, be improved and adapted to this legislative framework, including more physical layers depending on end-user requirements. Similarly, development of pelagic marine landscape maps could be combined with data on e.g. commercial fish species or marine mammals, to provide valuable information to improve management of the marine environment.

In conclusion, marine landscape mapping in the Baltic Sea region is just beginning and although much work has been put into this first step, there are still many challenges ahead. These include access to existing data from the entire Baltic region, assigning confidence ratings to the map, improving data layers classification and most importantly, providing good practice examples on how this characterisation can be applied in implementing EU legislation and planning.

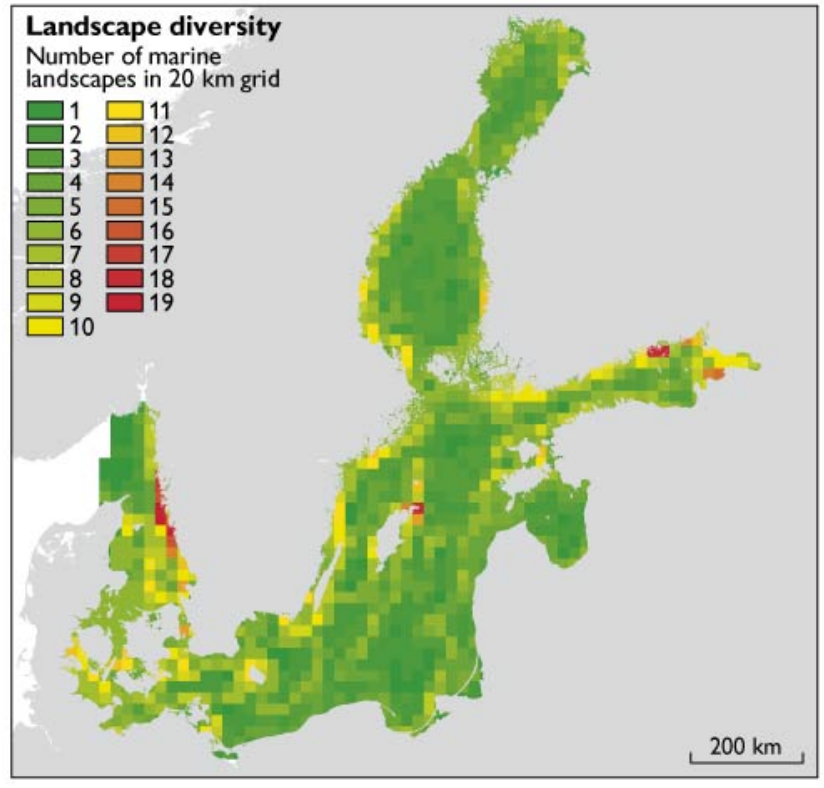

Fig. 6. Map showing diversity of marine landscape types.

\section{Acknowledgements}

Data, analysis and stimulating discussions for the production of the marine landscape maps were provided by David Connors (Joint Nature Conservation Committee UK), Karsten Dahl, Johan Söderkvist and Jørgen Bendtsen (National Environmental Research Institute, Denmark), Jesper H. Andersen and Anders Erichsen, (Danish Hydraulic Institute, Water Environment \& Health), Lisbeth Tougaard (Geological Survey of Denmark and Greenland) and Daria Ryabchuk (All-Russian Geological Institute, St. Petersburg).

\section{References}

Al-Hamdani, Z.K. \& Reker, J. (eds) in press: Towards marine landscapes in the Baltic Sea. Copenhagen: Geological Survey of Denmark and Greenland.

Connor, D.W., Golding, N., Robinson, P., Todd, D. \& Verling, E. 2006: UKSeaMap: The mapping of marine seabed and water column features of UK seas, 104 pp. Peterborough: Joint Nature Conservation Committee.

Day, J.C. \& Roff, J.C. 2000: Planning for representative marine protected areas: a framework for Canada's oceans, $147 \mathrm{pp}$. Toronto: World Wildlife Fund Canada.

Roff, J.C. \&. Taylor, M.E. 2000: Viewpoint. National frameworks for marine conservation - hierarchical geophysical approach. Aquatic Conservation. Marine and Freshwater Ecosystems 10, 209-223.

Segerstråle, S.G. 1957: The Baltic Sea. In: Hedgpeth, J.H. (ed.): Treatise on marine ecology and paleocology, 1. Ecology. Geological Society of America Memoir 67, 751-800.

\section{Authors' addresses}

Z.K.A. \& J.O.L., Geological Survey of Denmark and Greenland, Øster Voldgade 10, DK-1350 Copenhagen K, Denmark. E-mail: azk@geus.dk A.T.K. \& A.R., Geological Survey of Finland, P.O. Box 96, FIN-02151 Espoo, Finland.

J.R. \& G.E.D., Danish Forest and Nature Agency, Haraldsgade 53, DK-2100 Copenhagen Ø, Denmark. 